\title{
Ingreso vs gasto de gobierno: Evolución del Presupuesto General del Estado, Ecuador, periodo 2013 - 2017
}

\section{Income vs. government spending: Evolution of the General State Budget, Ecuador, 2013-2017 period}

\author{
Roberto Anthony Chafla Mona ${ }^{1}$ \\ robert.chafla11@gmail.com \\ Sergio Cristóbal Suárez López ${ }^{2}$ \\ ssuarez@utb.edu.ec \\ Darwin Jorge Gil Espinoza ${ }^{3}$ \\ dgil@utb.edu.ec
}

Recibido: 1/9/2019, Aceptado: 1/11/ 2019

\begin{abstract}
RESUMEN
Esta investigación se desarrolló en base a la necesidad de aportar y dar a conocer a la sociedad la información de la evolución del Presupuesto General del Estado, por el motivo de que como integrantes de una nación debemos estar pendiente de lo que sucede con los recursos financieros que genera nuestro país, la manera en que los representantes del gobierno gestionan los fondos públicos y como satisfacen las necesidades que el pueblo requiere, el proceso evolutivo se da a conocer en cifras económicas y cómo está compuesto el Presupuesto General del Estado, se determinara cuáles son los componentes que integran a los ingresos de gobierno, de la misma manera como están conformado los egresos de gobierno, establecemos datos monetarios de cada uno de los ingresos y egresos de gobierno, como consiguiente este estudio se lo realizo con los datos estadísticos nacionales que nos proporciona el ente rector de las finanzas de nuestro país como lo es el Ministerio de Economía y Finanzas del Ecuador, este ente nos proporcionó los datos de acuerdo a sus informes realizados de forma anual, donde constan los presupuestos ejecutados que fueron elaborados por periodo desde años anteriores, para llevar a cabo el estudio de nuestra investigación se tomó los datos de los presupuestos ejecutados y elaborados del periodo 2013-2017 en donde se establece tanto los componentes de los ingresos y sus valores monetarios además la distribución del uso de los fondos públicos de igual forma en valores monetarios, se determinara que componente de los ingresos es el que genera más fondos financieros al país, se estudiara el comportamiento del ingreso del petróleo y de la misma manera cuales son los gastos que generan más desembolso de dinero por parte del estado, analizaremos si hubo superávit o déficit presupuestario dentro de los años a estudiar, esto en sí, conlleva a que el gobierno logre cumplir con los objetivos implementados en el plan del buen vivir.
\end{abstract}

\footnotetext{
1 Universidad Técnica de Babahoyo, Ecuador

2 Universidad Técnica de Babahoyo, Ecuador

3 Universidad Técnica de Babahoyo, Ecuador
} 


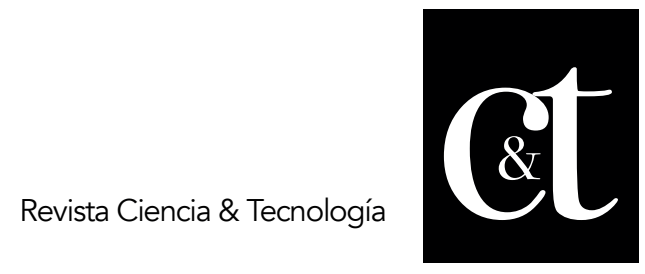

No. 25, 31 de enero de 2020

ISSN impreso: 1390 - 6321

ISSN online: 2661 - 6734

Palabras Clave: déficit, evolución del presupuesto, gasto público, ingreso público, superávit

\begin{abstract}
This research was developed based on the need to provide and make known to society the information on the evolution of the General State Budget, for the reason that as members of a nation we must be aware of what happens with financial resources generated by our country, the way in which government representatives manage public funds and how they meet the needs that the people require, the evolutionary process is made known in economic figures and how the General State Budget is composed, which they are the components that integrate government revenues, in the same way as government expenditures are made up, we establish monetary data of each of the government's income and expenditures, as a result of this study I do it with the national statistical data that It provides us with the governing body of the finances of our country as it is the Ministry of Economy and Fine Ecuador, this entity provided us with the data according to their annual reports, which show the executed budgets that were prepared by period from previous years, to carry out the study of our research took the budget data executed and elaborated from the period 20132017 where both the components of the income and their monetary values are established, as well as the distribution of the use of public funds in the same way in monetary values, it will be determined which component of income generates the most financial funds to the country, the behavior of oil income will be studied and in the same way which are the expenditures that generate more money outlay by the state, we will analyze if there was a budget surplus or deficit within the years to study, this in itself, leads to the government achieving compliance with the objectives implemented in the plan of good living.
\end{abstract}

Keywords: deficit, budget evolution, public expenditure, public income, surplus

\title{
Introducción
}

En muchos países a nivel mundial cuentan con un sistema de carácter democrático, en el cierre de un periodo fiscal tienen la obligación de dar a conocer al pueblo el presupuesto general del estado, tienen la responsabilidad de la elaborar y socializar de manera que sea transparente la información, no es más que establecer dichas proyecciones de los gastos públicos e implementar estrategias para recaudar los recursos que cubrirán dichos gastos.

El presupuesto del sector público se conforma por los ingresos de carácter público y los egresos públicos, dentro de lo que respecta a ecuador nos dice que dentro de las normas y leyes establece que los ingresos se clasifican en permanentes y no permanentes, como podremos apreciarlo más adelante los ingresos permanentes son aquellos que se perciben de manera periódica y permanente como por ejemplo la recaudación de los ingresos que en la actualidad son la mayor fuente de ingreso público, y aquellos no permanentes son los no periódicos y no son repetitivos como por ejemplo la venta de un activo público improductivo que por lo general no se da permanentemente. 


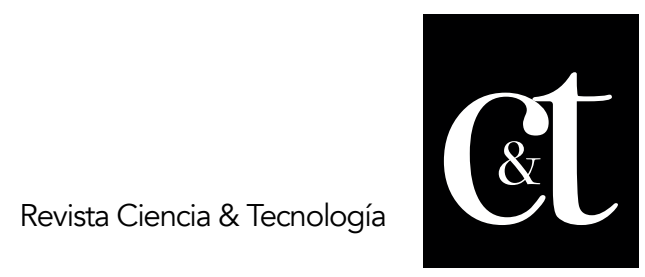

No. 25, 31 de enero de 2020

ISSN impreso: 1390 - 6321

ISSN online: 2661 - 6734

De la misma forma la composición del presupuesto está conformada por sus respectivos egresos de los cuales son los permanentes y no permanentes, el primero nos dice que son aquellos egresos que se da de manera periódica y es constante cada periodo fiscal como por ejemplo cubrir las necesidades primordiales de la sociedad que son salud, vivienda, alimentación, transporte, electricidad, etc. Por su parte los no permanentes son los que no se dan de manera repetitiva como por ejemplo gastos de mantenimiento en el sector público que por lo general no se dan regularmente.

Dentro de la relación de estos dos componentes fundamentales del presupuesto se puede dar tanto superávit como déficit, el superávit se da cuando los ingresos son mayores a los egresos y por su parte el déficit que se da cuando los egresos son mayores a los ingresos.

Para ser eficiente en el ámbito de la elaboración y ejecución de un presupuesto el gobierno debe saber gestionar los fondos públicos, se debe establecer lineamientos como los implementados por el ente regulador que será la secretaria nacional de planificación y desarrollo, que establecerá normas y procedimientos a cada nivel de gobierno, instituciones, entidades y organismos que deban presentar su planificación de gastos que requieran para ejecutar sus actividades.

\section{Desarrollo}

Presupuesto público. Ortiz Bojaca (2005) menciona que sobre el presupuesto público existen variedades de conceptos que tienen relación tanto con su origen como acto soberano de los que contribuyen al mismo. De esta manera se puede definir al presupuesto público como un estado en el que se perciben y prevén ingresos y gastos durante un determinado periodo de tiempo, es un cuadro que evalúa y compara los gastos que deben satisfacerse y los ingresos que han de percibirse. Además, se puede decir que el presupuesto es una ley complementaria y de carácter temporal, se debe a que todo ingreso y gasto para incluirse en el mismo debe tener previamente autorización por otra ley.

De la misma manera para el Ministerio de Economía y Finanzas (2017) el presupuesto general del estado ecuatoriano es el instrumento fundamental de la política fiscal para poder determinar la administración y gestión de los respectivos ingresos y egresos de las entidades que conforman las diferentes funciones o poderes del estado, el gobierno influye en los agregados económicos, así como en la ejecución adecuada del ente rectos de las finanzas del estado, se determina que las entidades y respectivos organismos deben gestionar de manera programada y con criterio de calidad los ingresos y egresos de financiamiento de conformidad con sus presupuestos institucionales.

El estado es quien ejerce el poder democrático, público, porque es el representante jurídico de la nación y por ende debe organizarse para atender a todo los que conforman el pueblo mediante sus diferentes niveles de gobierno, el estado en si es como una gran empresa que se organiza para administrar los recursos, por lo tanto para poder administrar el país cuenta con sus poderes que son el legislativo, ejecutivo, judicial, electora, transparencia y control social (Romero Romero, 2013). 


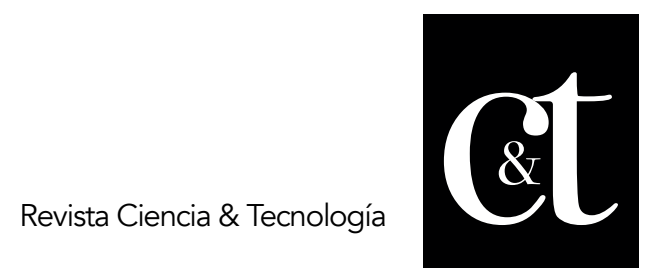

No. 25, 31 de enero de 2020

ISSN impreso: 1390 - 6321

ISSN online: 2661 - 6734

La importancia del presupuesto público radica en que es el instrumento de actuación y el que, junto a la política monetaria, tiene una gran influencia en la modificación de los movimientos no deseados de una economía de mercado, dada su posibilidad de actuación como política compensatoria. El presupuesto no se centra exclusivamente en aquellos gastos de que son necesarios para la actividad clásica de un estado, sino que en su contenido se integran gastos de carácter económico que influyen directamente sobre todas las actividades económicas de un país (León Gutiérrez, Escobar Gallo, \& Gutiérrez Londoño, 2007).

De acuerdo con (Ministerio de Economía y Finanzas, 2018a) establece que el presupuesto general del estado es la estimación de los recursos financieros que tiene el ecuador, quiere decir que qui se encuentran los ingresos que recauda el estado como son los provenientes de la venta del crudo de petróleo y sus derivados, la recaudación de impuestos o tributos, etc. Por otro lado, se encuentran los gastos que estos son aquellos que se otorga al pueblo en servicio, producción y aquellos que son importantes para el desarrollo y funcionamiento estatal para la educación, salud, agricultura, vivienda, seguridad, electricidad y transporte, etc. De acuerdo a las necesidades que se presentan en los diferentes sectores del país y la programación de programas y proyectos de desarrollo.

Como establece el Ministerio de Economía y Finanzas (2010) en su artículo 78 la clasificación de los ingresos fiscales que son ingresos permanentes y no permanentes, en el cual establece que los ingresos permanentes son aquellos recursos públicos que el estado adquiere a través de sus entidades, instituciones y organismos estos se reciben de manera temporal por una situación específica. Los ingresos no permanentes son aquellos recursos públicos que el estado percibe de manera temporal por una situación específica o extraordinaria. En este mismo código establece en su artículo 79 la clasificación de los egresos fiscales que son los permanentes y no permanentes, en el cual los egresos permanentes son aquellos que otorga el estado a través de sus entes, son de carácter operativo que requieren repetición permanentes y permiten la provisión continua de bienes y servicios públicos a la sociedad, mientras que los egresos no permanentes son los que se efectúan de carácter temporal por una situación específica o extraordinaria y no requiere de repetición permanente.

Por su parte Velásquez Trejo (2010) confirma que los ingresos públicos son un conjuntos de adquisiciones económicas que un estado obtiene, en conformidad a dos grupos los ingresos ordinarios y extraordinarios, los ordinarios corresponden aquellos que se perciben regularmente, son repetitivos en cada ejercicio fiscal, mientras que los extraordinarios son aquellos que se perciben solo cuando circunstancias anormales al estado frente a necesidades imprevistas que lo obligan a obtener ingresos extraordinarios. Para Ayala Espino (2001) el gasto público se refiere al valor total de las compras de bienes y servicios realizados por el sector gubernamental durante un periodo o ciclo productivo, incluye gastos de inversión y de consumo. Intervienen los gastos o egresos direccionados a las áreas de más necesidad que es de carácter obligatoria del estado como son educación, vivienda, salud, alimentación, etc. 
El presupuesto fiscal se elabora, ejecuta y se controla por medio de un proceso que lo establece el ente regulador, llamado ciclo presupuestario, que tiene lugar a un periodo determinado y este cumple distintas etapas o fases principales para su elaboración, aprobación y ejecución.

El objetivo del Ministerio de Economía y Finanzas (2018c) es regular la administración del componente presupuestario en las fases de programación; formulación; aprobación; ejecución; evaluación y seguimiento, y, clausura y liquidación presupuestaria.

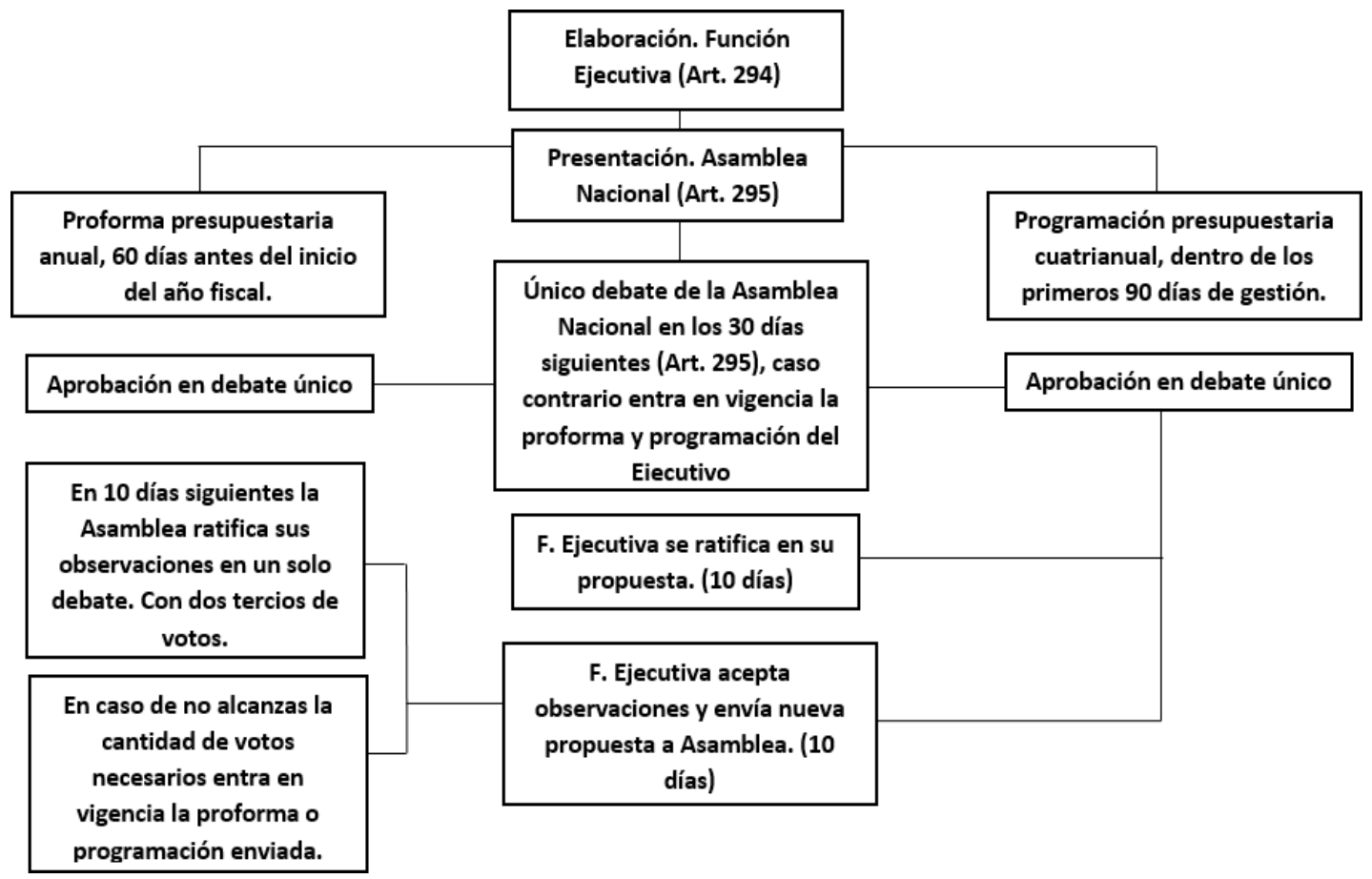

\section{Gráfico 1. Elaboración y aprobación del Presupuesto General del Estado, Ecuador \\ Fuente: Asamblea Nacional del Ecuador, 2008}

Elaborado por: Autores

\section{Materiales y métodos. Tipo de investigación}

En el presente contexto de investigación de este estudio se ha tomado en consideración la implementación de la investigación no experimental. Como lo mencionan Toro Jaramillo y Parra Ramírez (2006), la investigación no experimental es aquella que se realiza sin manipular deliberadamente las variables independientes.

Lo que se realiza en la investigación no experimental es la observación de fenómenos tal y como se dan en su contexto natural, para luego realizar el análisis. Por decirlo de alguna forma en un experimento se concluye una realidad en cambio en un estudio o investigación no experimental no se construye ninguna situación, sino que se observan situaciones ya existentes no provocadas de manera intencionada por el investigador.

Se implementó su uso con la finalidad de emitir criterios de consideración que se 


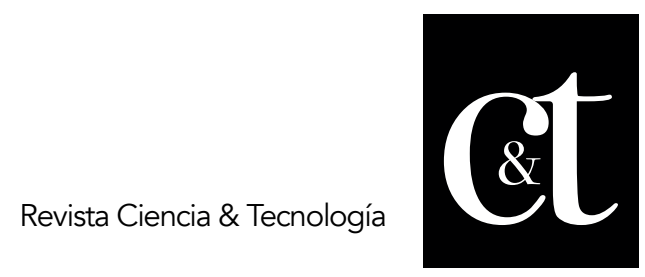

No. 25, 31 de enero de 2020

ISSN impreso: 1390 - 6321

ISSN online: 2661 - 6734

encuentren establecidos en las conclusiones a las que llegaremos con el desarrollo de la investigación realizada.

\section{Métodos}

El método establecido para esta investigación es el método inductivo - deductivo como lo menciona (Bernal Torres, 2006) que es un método de inferencia basado en la lógica y relacionando con el estudio de hechos particulares, aunque es deductivo es un sentido (parte de lo general a lo particular) e inductivo en sentido contrario (va de lo particular a lo general).

Se lo acogió con el motivo de profundizar más allá de lo concerniente al Presupuesto General del Estado, arrancando de las normas y lineamientos que permiten la recaudación y obtención de los fondos necesarios para cubrir los gastos públicos.

Además, también se optó por implementar el método analítico sintético como establecen Hurtado y Toro Garrido (2007), en cuanto consiste en la descomposición mental del objeto estudiado en sus distintos elementos o partes componentes para obtener nuevos conocimientos acerca de dicho objeto.

Se lo implementó con el fin de analizar los resultados que se obtuvieron mediante la ejecución de la investigación bibliográfica correspondiente a la información que se obtuvo de la fuente primordial para realizar este estudio como lo es el ente recto de las finanzas públicas del ecuador.

\section{Técnicas}

La técnica de bibliografía documentada permitió que se establezcan análisis profundizados de la información publicada por el ente rector de las finanzas públicas en relación al Presupuesto General del Estado durante el estudio realizado en el periodo 2013 - 2017, que aporto para determinar cómo ha evolucionado y cuáles son los principales componentes que forman parte del mismo, de la misma manera las fuentes de financiamiento que permiten la sostenibilidad de los rubros competentes en los que interviene el gobierno para otorgar un bienestar social al pueblo.

\section{Resultados}

Análisis estadístico del Presupuesto General del Estado, Ecuador, periodo 2013 2017 Gráfico 2. Detalle de ingresos y gastos de gobierno 2013 (millones de dólares). 


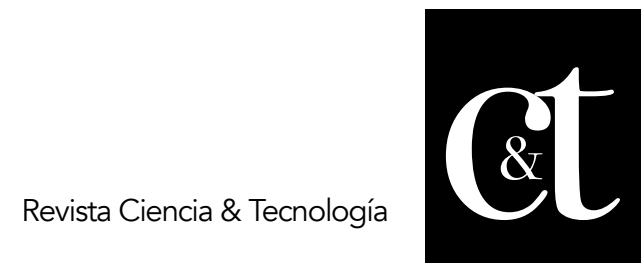

No. 25, 31 de enero de 2020

ISSN impreso: 1390 - 6321

ISSN online: 2661 - 6734

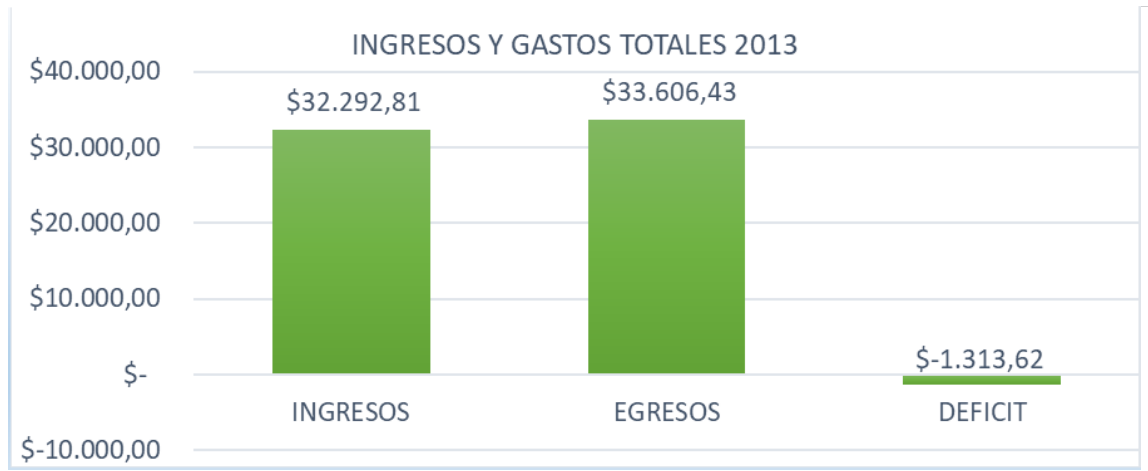

Gráfico 2. Detalle de ingresos y gastos de gobierno 2013 (millones de dólares) Fuente: Ministerio de Finanzas, 2014

Elaborado por: Autores

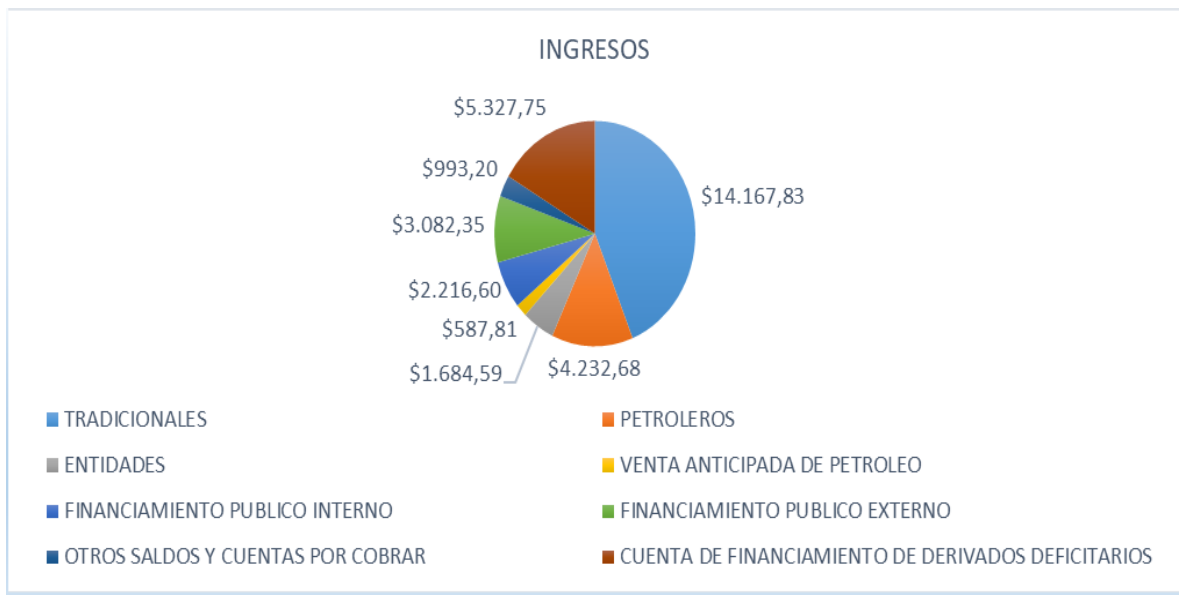

Gráfico 3. Recaudación de ingresos de gobierno 2013

Fuente: Ministerio de Finanzas, 2014

Elaborado por: Autores 


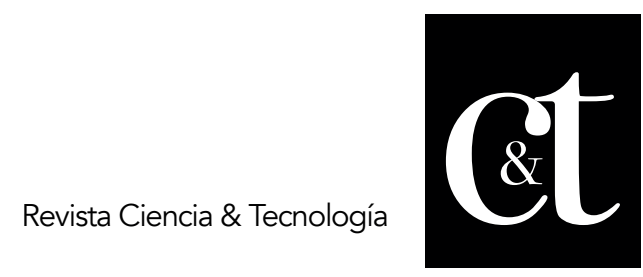

No. 25, 31 de enero de 2020

ISSN impreso: 1390 - 6321

ISSN online: 2661 - 6734

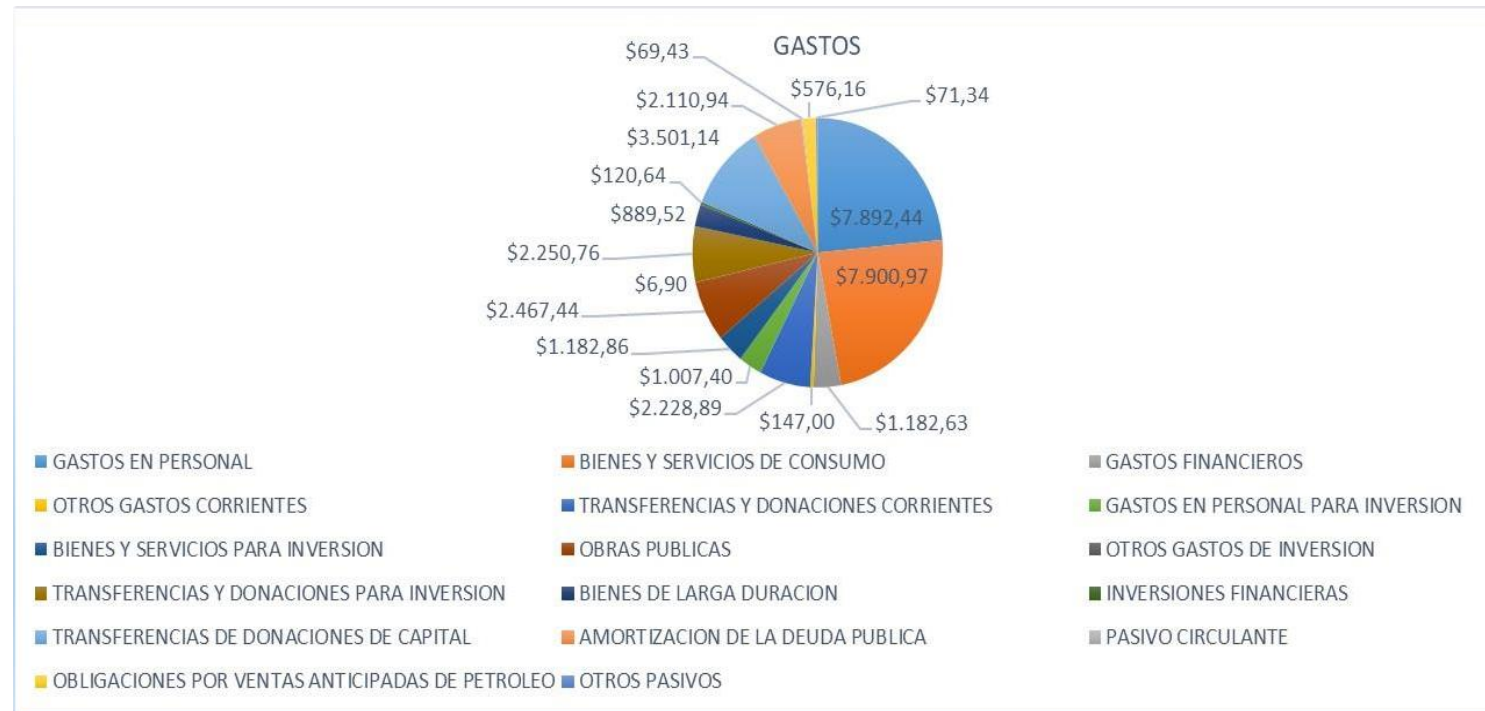

\section{Gráfico 4. Distribución de gastos de gobierno 2013}

Fuente: Elaboración propia.

De acuerdo con la información del año 2013 nos podemos dar cuenta que los egresos superaron a los ingresos obteniendo de esta manera un déficit en el presupuesto de $\$ 1.313,62$ millones de dólares, dentro de los ingresos los mayores rubros recaudadores son los tradicionales que son los provenientes de los impuestos que generan un $43.87 \%$ del total de ingresos y el petrolero un $13.11 \%$, por el otro lado los egresos más altos en los que distribuye el estado son los gastos del personal que genera un $23,48 \%$ del total de los egresos y los bienes y servicios de consumo que cubre un $23,51 \%$.

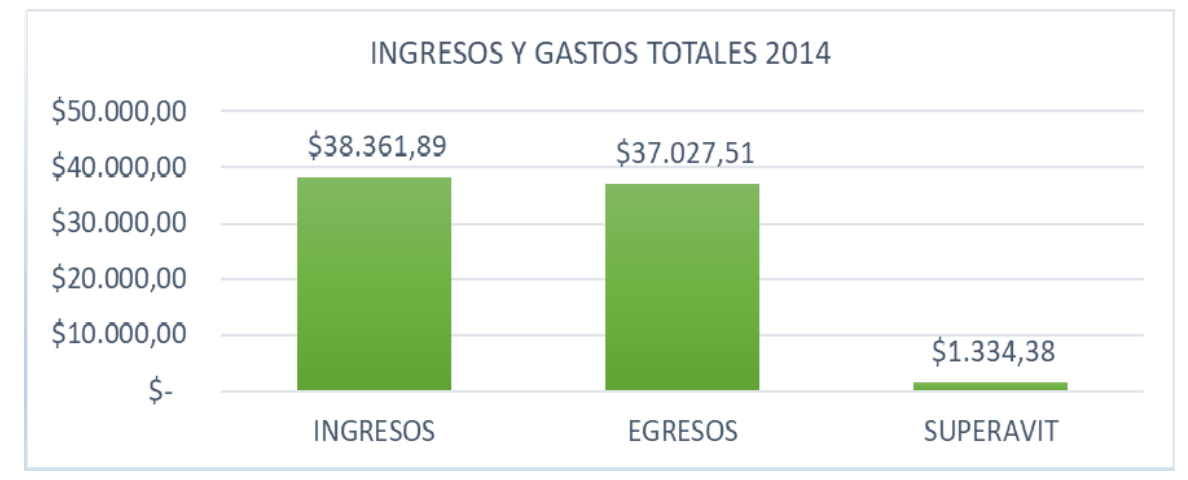

\section{Gráfico 5. Detalle de ingresos y gastos de gobierno 2014 (millones de dólares).}

Fuente: Ministerio de Finanzas, 2015

Elaborado por: Autores 


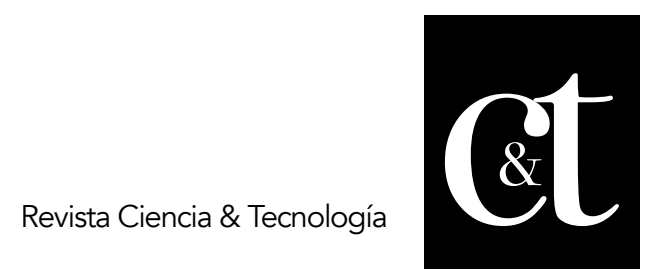

No. 25, 31 de enero de 2020

ISSN impreso: 1390 - 6321

ISSN online: 2661 - 6734

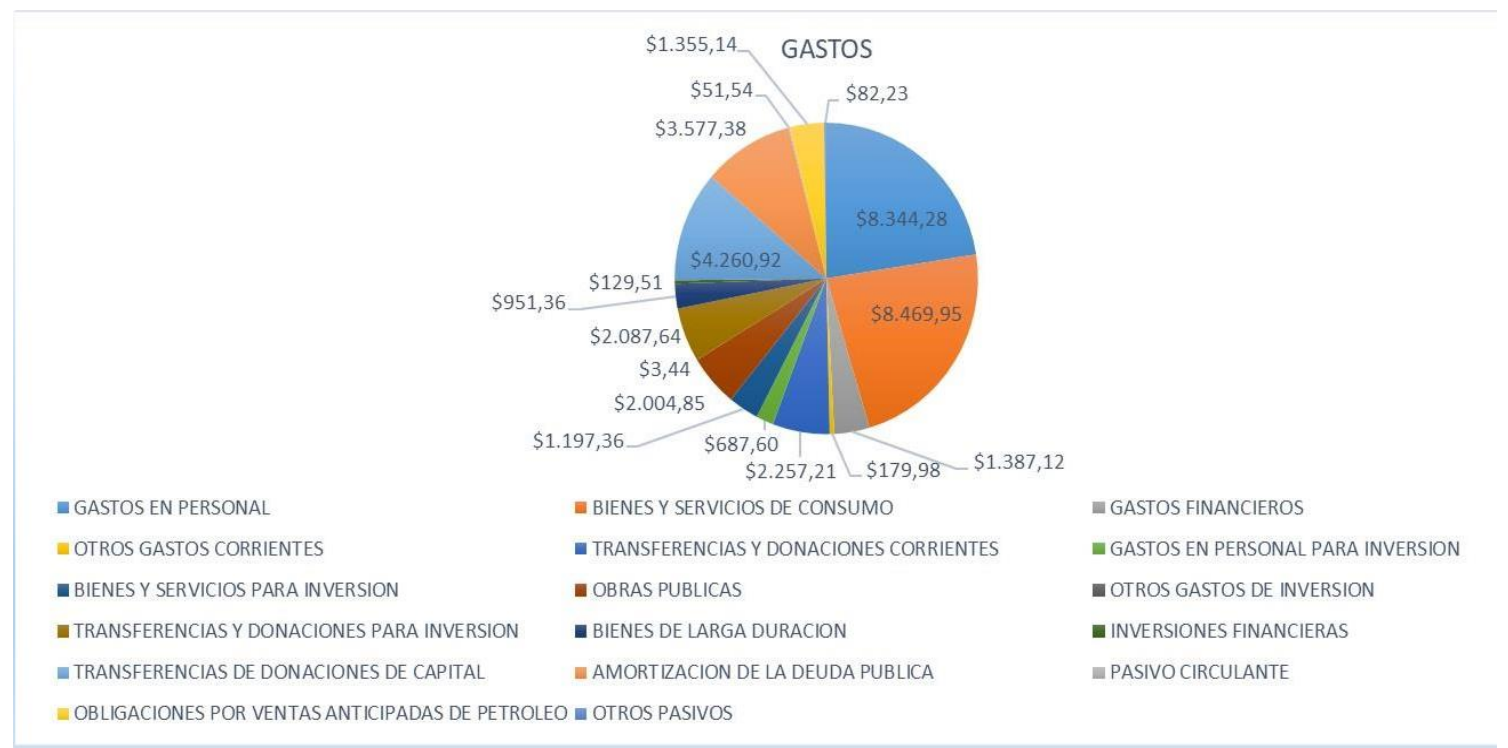

Gráfico 6. Distribución de gastos de gobierno 2014

Fuente: Ministerio de Finanzas, 2015

Elaborado por: Autores

En este año 2014 en comparación al anterior se produjo un superávit de $\$ 1.334,38$ pero hay una particularidad en que los ingresos petroleros ocupan solo un $5,33 \%$ del total de los ingresos anteriormente ocupaban el $13.11 \%$ es decir disminuyo el ingresos de petróleo en un $7,78 \%$ mientras que por su parte los ingresos tradicionales por impuestos pasaron de un $43,87 \%$ del año anterior a un 39,34\% provocando una disminución del 4,53\%, mientras que los demás rubros que participan crecieron proporcionalmente, por su parte en los egresos el rubro gastos de personal paso del $23.48 \%$ del año anterior a $22.54 \%$ ocasionando una disminución de $0,94 \%$, el rubro bienes y servicios de consumo paso de un $23,51 \%$ del año anterior a un $21,87 \%$ ocasionando una disminución del $1,64 \%$, mientras que los demás rubros de egresos disminuyeron proporcionalmente. 


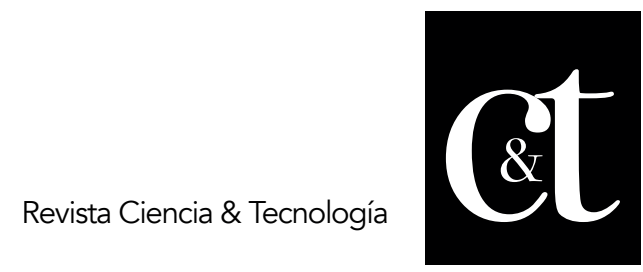

No. 25, 31 de enero de 2020

ISSN impreso: 1390 - 6321

ISSN online: 2661 - 6734

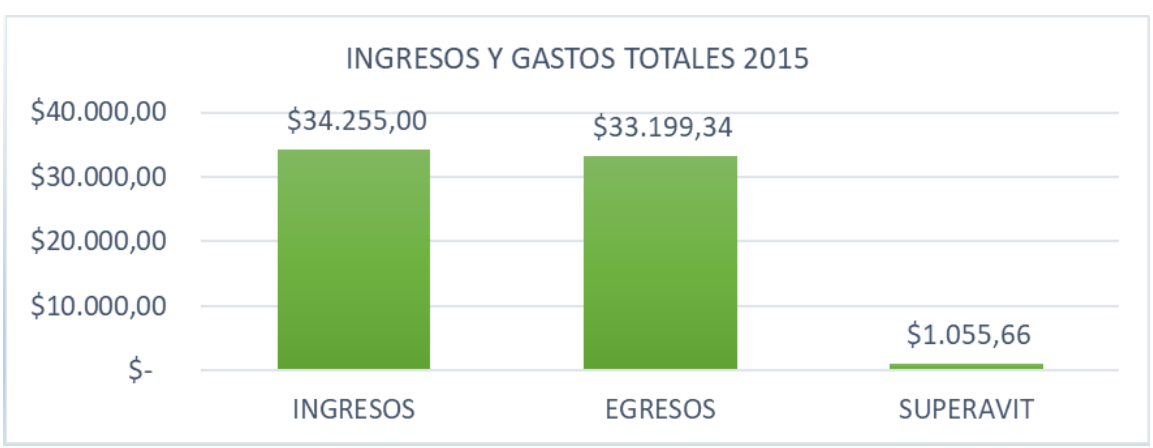

Gráfico 7. Detalle de ingresos y gastos de gobierno 2015 (millones de dólares). Fuente: Ministerio de Finanzas, 2016

Elaborado por: Autores

- TRADICIONALES

ENTIDADES

- FINANCIAMIENTO PUBLICO INTERNO

- otROS SALDOS Y CUENTAS POR COBRAR
INGRESOS

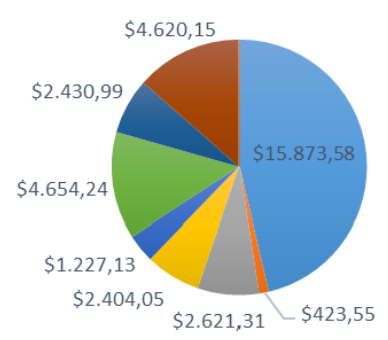

a PETROLEROS

= VENTA ANTICIPADA DE PETROLEO

a FINANCIAMIENTO PUBLICO EXTERNO

- CUENTA DE FINANCIAMIENTO DE DERIVADOS DEFICITARIOS

Gráfico 8. Recaudación de ingresos de gobierno 2015

Fuente: Ministerio de Finanzas, 2016

Elaborado por: Autores 


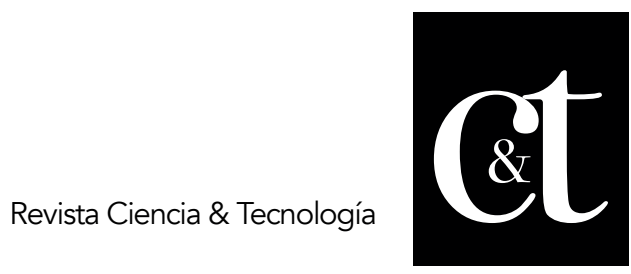

No. 25, 31 de enero de 2020

ISSN impreso: 1390 - 6321

ISSN online: 2661 - 6734

GASTOS EN PERSONAL

॥ AMORTIZACION DE DEUDA PUBLICA

- RANSFERENCIASY DONACIONES CORRIENTES

- BIENES Y SERVICIOS PARA NVERSION

ఐ OTROSGASTOS CORRIENTES

= OTROS GASTOS DE INVERSION

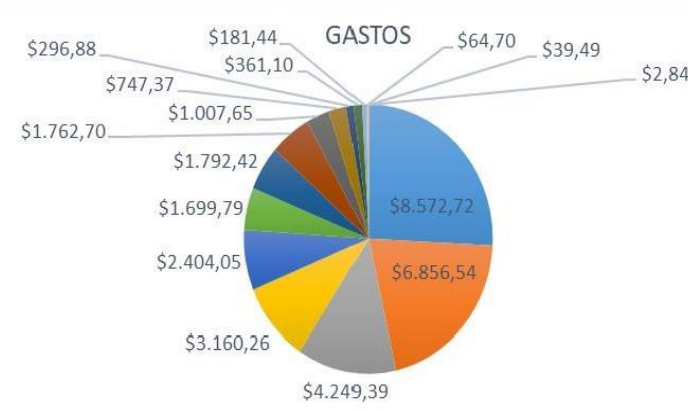

- BIENES Y SERVICIOS DE CONSUMO

- TRANSFERENCIAS Y DONACIONES DE CAPTTAL

- OBLIGACIONES POR VENTAS ANTICIPADAS DE PETROLEO = TRANSFERENCIAS Y DONACIONES PARA INVERSION

- GASTOS FINANCIEROS

- OBRAS PUBLICAS

- BIENES DE LARGA DURACION

=OTROS PASIVOS

- GASTOS EN PERSONAL PARA INVERSION

- INVERSIONES FINANCIERAS

Gráfico 9. Distribución de gastos de gobierno 2015

Fuente: Ministerio de Finanzas, 2015

Elaborado por: Autores

Este año 2015 en relación al año anterior también se produjo un superávit de \$ $1.055,66$ millones de dólares, en el cual los rubros más fuertes como el ingreso tradicional de impuestos paso de un 39,34\% del año anterior a un $46.34 \%$ es decir aumentó en un $7 \%$ mientras que el rubro de ingreso de petróleo pasó de un $5,33 \%$ del año anterior a un 1,24\% provocando una disminución del 4,09\%, podemos ver que el ingreso del petróleo no es muy representativo en los ingresos en este año. Por su parte en los rubros de los egresos, el de gastos en personal pasó de $22,54 \%$ del año anterior a un $25,83 \%$ provocando un aumento del $3.29 \%$, y en los bienes y servicios de consumo pasó de un $21,87 \%$ del año anterior a un $20,65 \%$ provocando una disminución de $1.22 \%$.

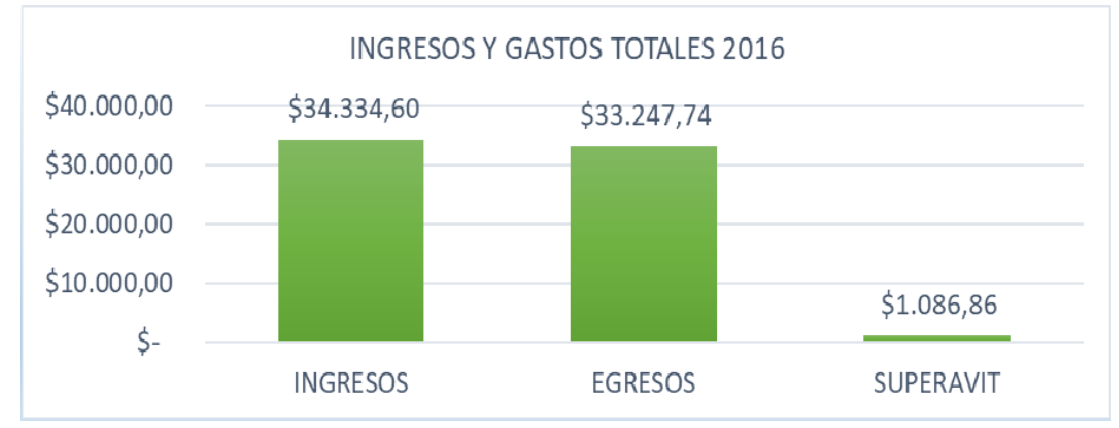

\section{Gráfico 10. Detalle de ingresos y gastos de gobierno 2016 (millones de dólares)}

Fuente: Ministerio de Finanzas, 2017

Elaborado por: Autores 


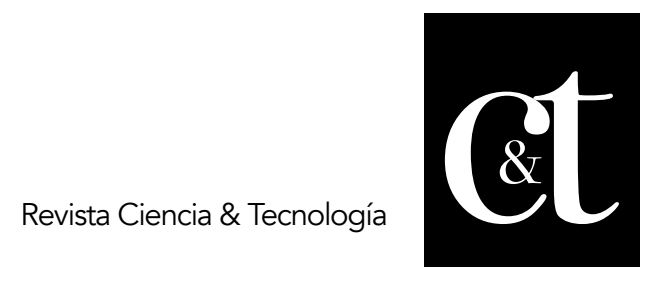

No. 25, 31 de enero de 2020

ISSN impreso: 1390 - 6321

ISSN online: 2661 - 6734

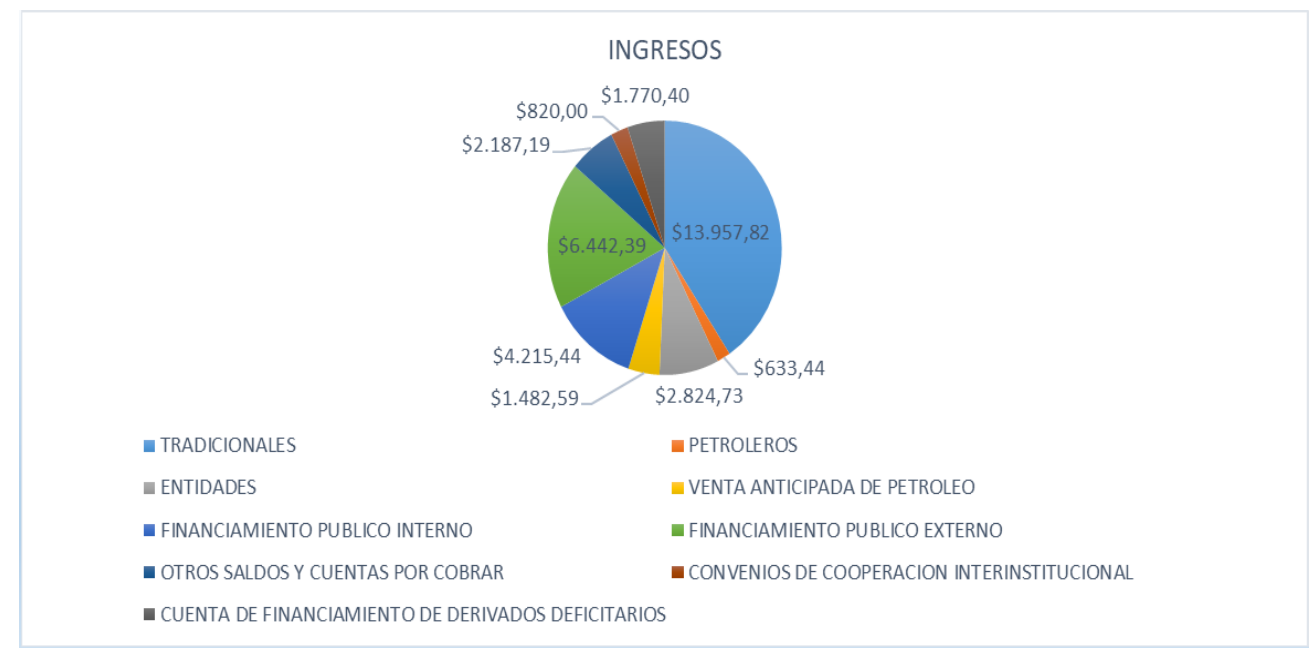

Gráfico 11. Recaudación de ingresos de gobierno 2016 Fuente: Ministerio de Finanzas, 2017

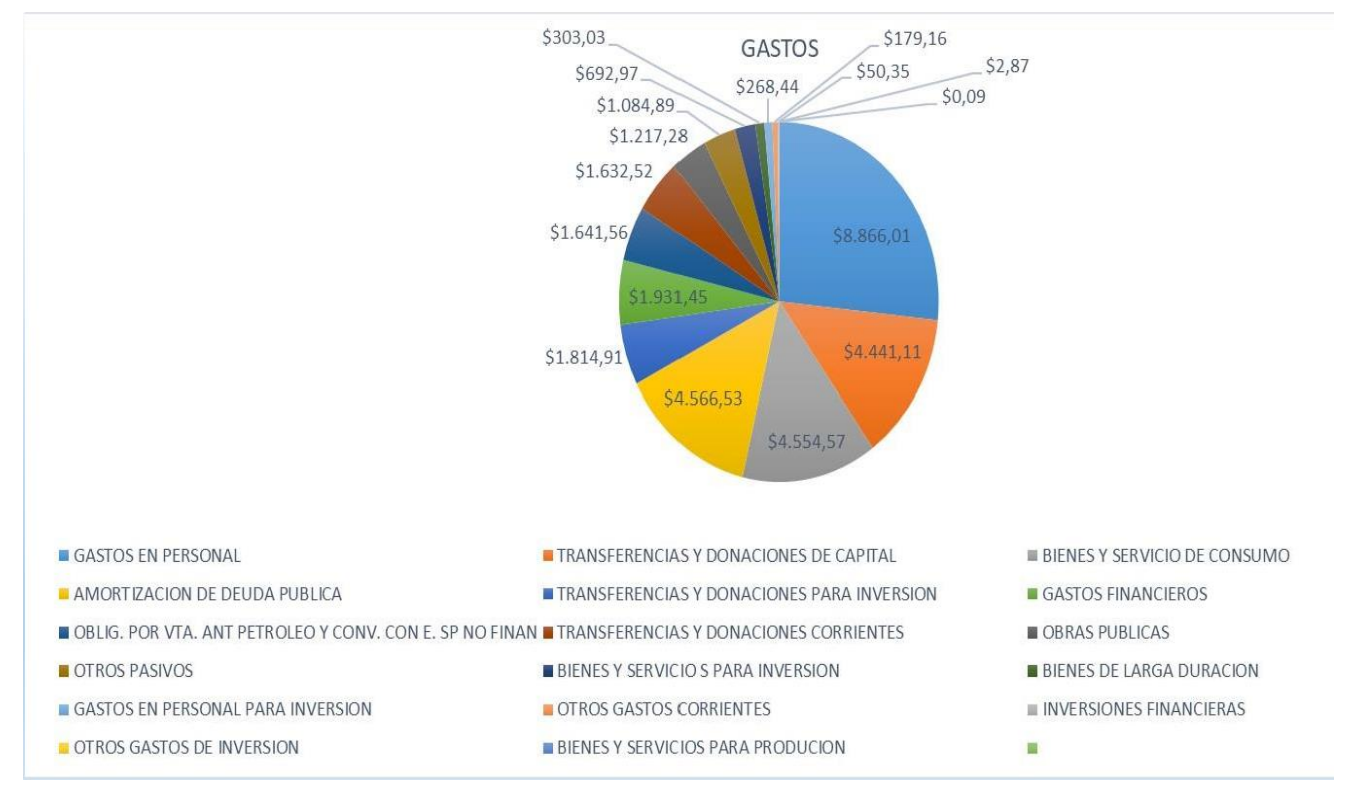

Gráfico 12. Distribución de gastos de gobierno 2016

Fuente: Ministerio de Finanzas, 2016

Elaborado por: Autores

En este año 2016 los ingresos fueron mayores que los egresos; por ende, se produjo un superávit en el presupuesto de $\$ 1.086,86$ millones de dólares, en el que los rubros de los ingresos más representativos, como el ingreso tradicional de impuesto, pasaron de $46,34 \%$ del año anterior a un $40,65 \%$ provocando una disminución de un $5.69 \%$. 


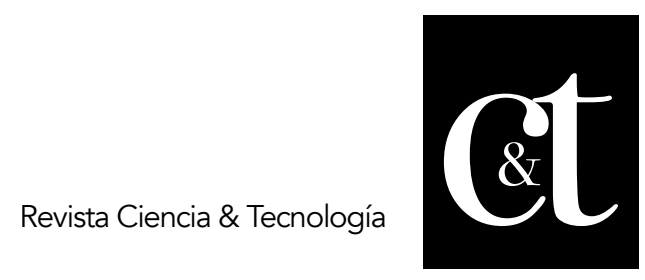

No. 25, 31 de enero de 2020

ISSN impreso: 1390 - 6321

ISSN online: 2661 - 6734

De la misma manera el rubro de ingresos petroleros pasó de $1,24 \%$ del año anterior a un $1,84 \%$. Podemos observar que el ingreso por petróleo ya no es tan representativo con años anteriores aunque este año aumento no es lo proporcionalmente considerable, los rubros considerables de los egresos como lo es el de gastos en personal paso de un $25,83 \%$ del año anterior a un $26,67 \%$ provocando un aumento de $0,84 \%$, mientras que el rubro bienes y servicio de consumo pasó de un $20,65 \%$ del año anterior a $13,70 \%$ provocando una disminución de 6,95\%.

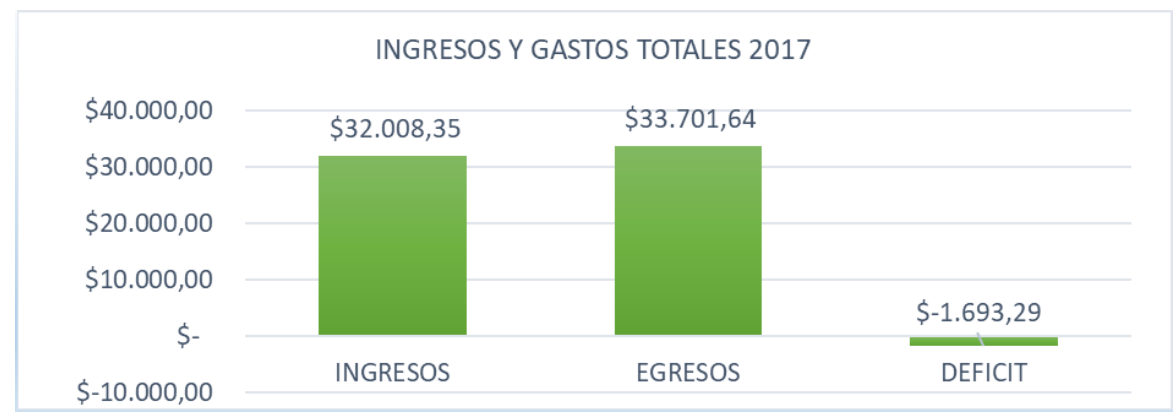

\section{Gráfico 13. Detalle de ingresos y gastos de gobierno 2017 (millones de dólares)}

Fuente: Ministerio de Economía y Finanzas, 2018

Elaborado por: Autores

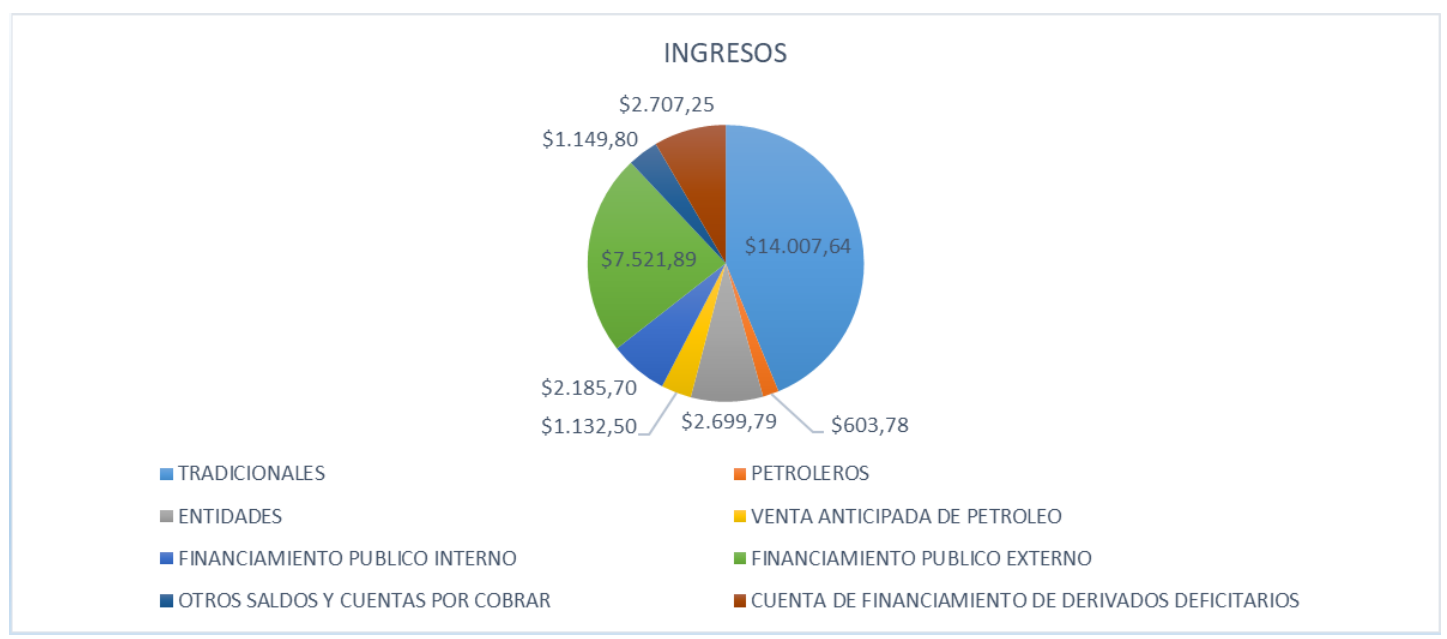

Gráfico 14. Recaudación de ingresos de gobierno 2017

Fuente: Ministerio de Economía y Finanzas, 2018

Elaborado por: Autores 


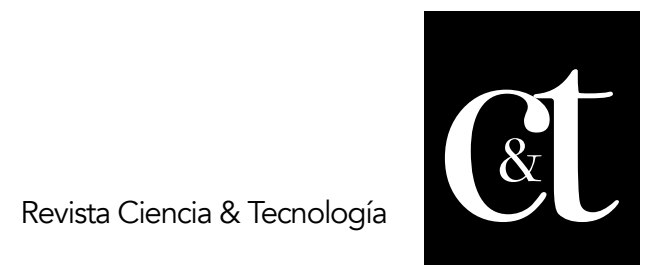

No. 25, 31 de enero de 2020

ISSN impreso: 1390 - 6321

ISSN online: 2661 - 6734

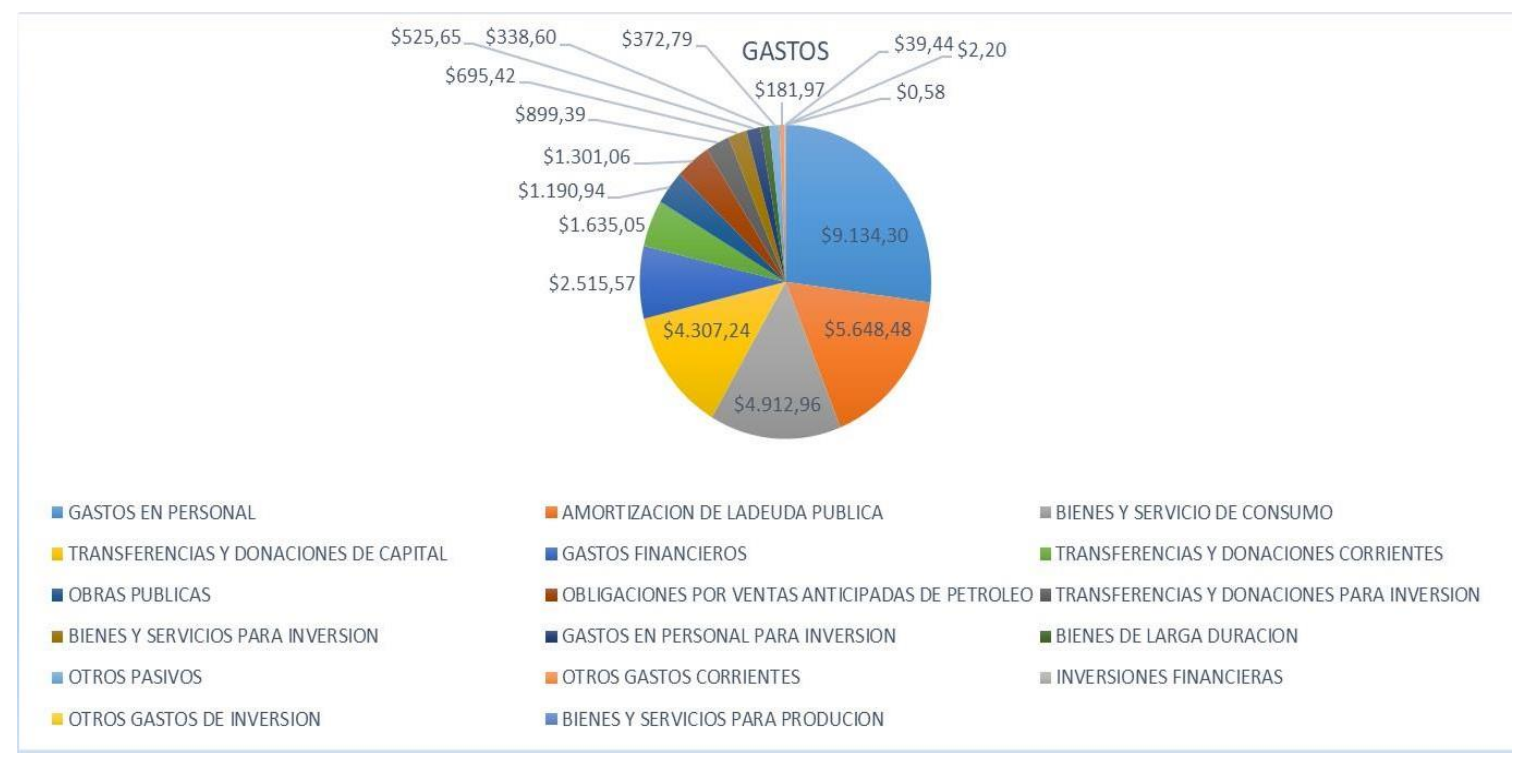

Gráfico 15. Distribución de gastos de gobierno 2017

Fuente: Ministerio de Economía y Finanzas, 2018

Elaborado por: Autores

En este año 2017 los egresos superaron a los ingresos provocando un déficit presupuestario de \$1.693,29 millones de dólares, dentro de los rubros más representativos que se han venido dando durante años de los que recaudan más ingresos como lo es el ingreso tradicional de impuestos que paso de $40,65 \%$ del año anterior a un $43,76 \%$ ocasionando un aumento del $3.11 \%$ mientras que los ingresos petroleros pasaron de $1,84 \%$ del año anterior a un $1,89 \%$ ocasionando un aumento de $0,05 \%$ manteniéndose la proporcionalidad del ingreso pero hay que acotar que nos podemos dar cuenta claramente que este rubro ya no proporciona el nivel de ingreso que se daba en años anteriores, dentro de los egresos más representativos como el de gastos en personal paso de $26,67 \%$ del año anterior a un $27,10 \%$ ocasionando un aumento de 0,43 manteniendo el nivel de gasto de personal, mientras que el rubro de bienes y servicios de consumo paso de $13,70 \%$ del año anterior a un $14,58 \%$ provocando un 0,88 manteniendo el nivel de gastos de bienes y servicios de consumo. 


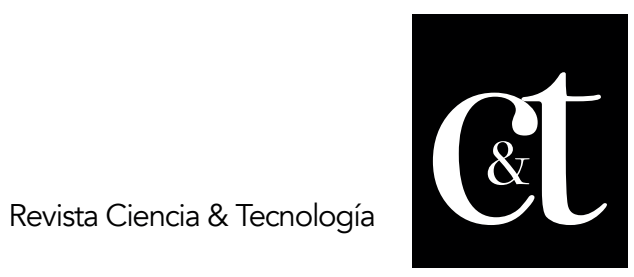

No. 25, 31 de enero de 2020

ISSN impreso: 1390 - 6321

ISSN online: 2661 - 6734

EVOLUCION DEL PRESUPUESTO 2013 - 2017

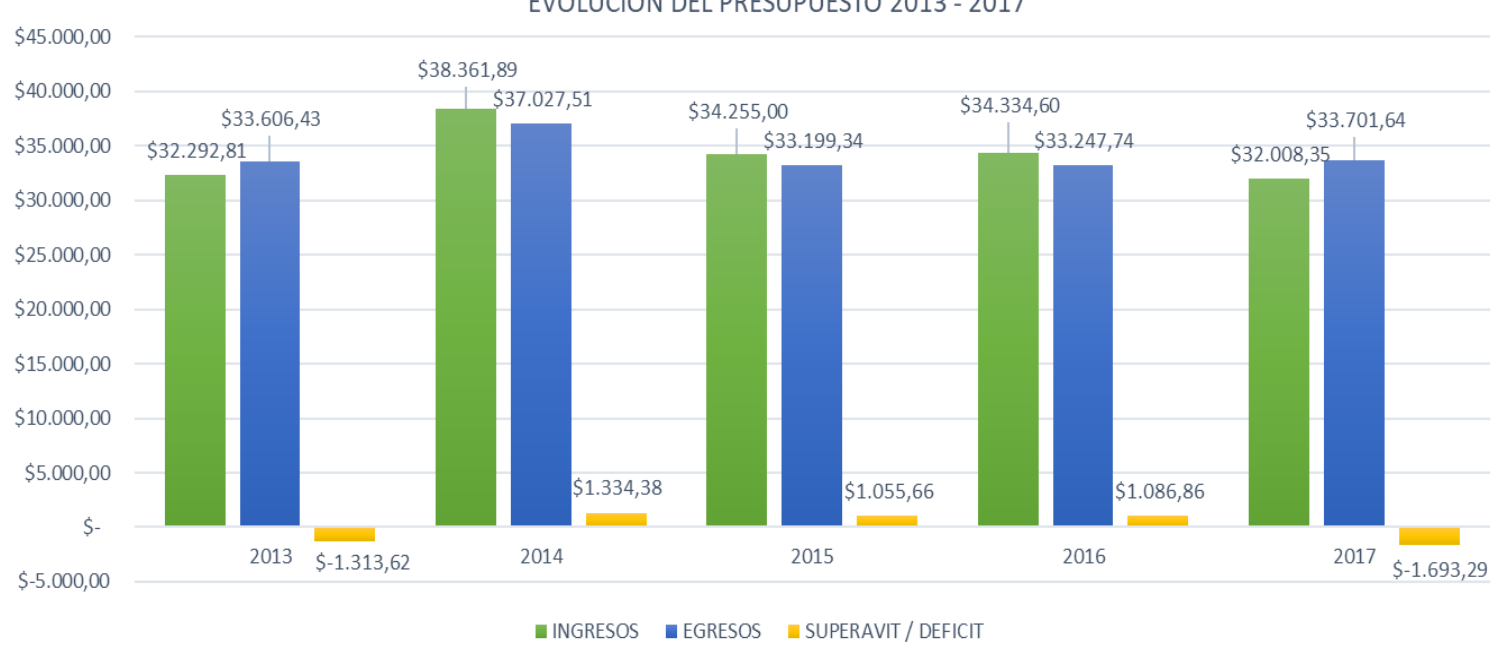

Gráfico 16. Evolución del Presupuesto General del Estado, Ecuador, periodo 2013 - 2017 (millones de dólares)

Fuente: Ministerio de Finanzas del Ecuador

Elaborado por: Autores

De acuerdo con el grafico 16 podemos realizar el respectivo análisis sobre la evolución del Presupuesto General del Estado Ecuatoriano, periodo 2013 - 2017, de acuerdo a los resultados en el año 2013 los ingresos fueron de \$32.292,81 millones de dólares y los gastos fueron de $\$ 33.606,43$ millones de dólares, su punto más alto lo alcanzo en el año 2014 donde los ingresos fueron de \$38.361,89 millones de dólares y los egresos \$37.027,51 millones de dólares, desde entonces hasta el año 2017 se ha producido un decrecimiento; además se puede observar que se produjo un déficit en el año 2013 de $\$ 1.313,62$ millones de dólares y el en año 2017 de la misma forma se produjo un déficit de $\$ 1.693,29$ millones de dólares, a diferencia de los demás periodos fiscales participantes que mostraron un superávit presupuestario. 


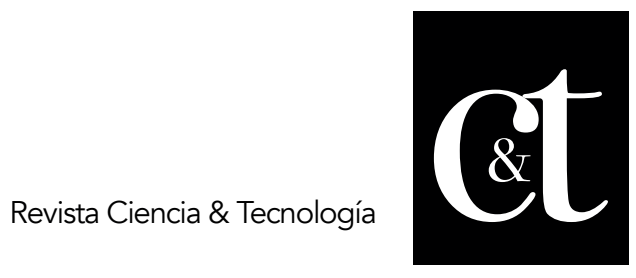

No. 25, 31 de enero de 2020

ISSN impreso: 1390 - 6321

ISSN online: 2661 - 6734

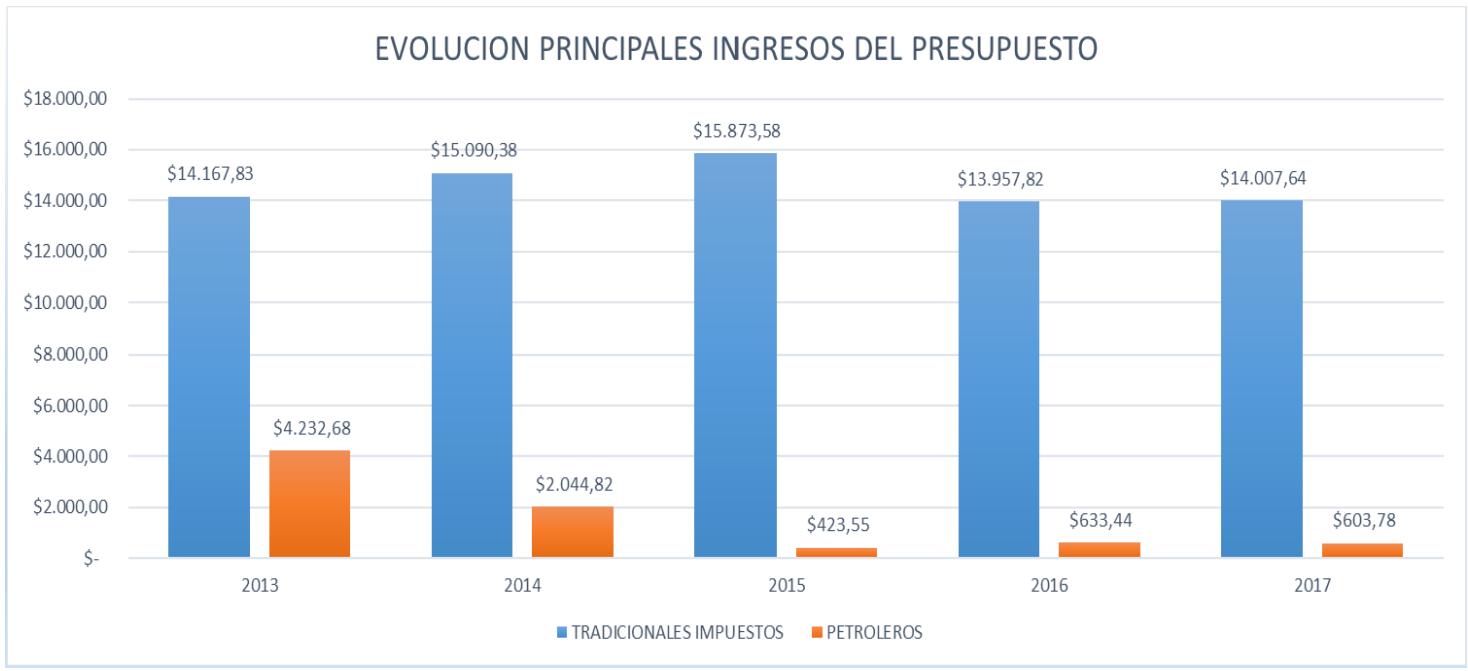

\section{Gráfico 17. Evolución de los principales ingresos que conforman el Presupuesto General del Estado, Ecuador, periodo 2013 - 2017 (millones de dólares)}

Fuente: Ministerio de Finanzas del Ecuador

Elaborado por: Autores

En la presente ilustración se establece un análisis de los principales ingresos del presupuesto general del estado ecuatoriano periodo 2013 - 2017, como sabemos nuestro país los principales ingresos provienen de la recaudación de los impuestos que son los tradicionales y los petroleros y sus derivados, entonces de estos dos quien más recauda fondos para el estado son los impuestos, en este estudio de 5 años atrás el punto más alto es el año 2015 con \$15,873,58 millones de dólares pero ha mantenido la proporcionalidad de ingresos estable no variando mucho, mientras que el otro rubro de ingresos como lo es del petróleo y sus derivados hace varios años atrás generaba muchos ingresos en relación a lo que proporciona ahora el este estudio en el año 2013 fue su punto más alto con una recaudación de $\$ 4,232,68$ millones de dólares desde ahí podemos observar que ha venido en decrecimiento hasta el año 2017, se puede acotar que la riqueza proveniente del petróleo ya no es una garantía para nuestro país. 


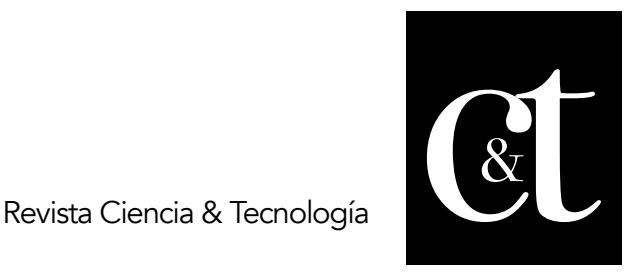

No. 25, 31 de enero de 2020

ISSN impreso: 1390 - 6321

ISSN online: 2661 - 6734

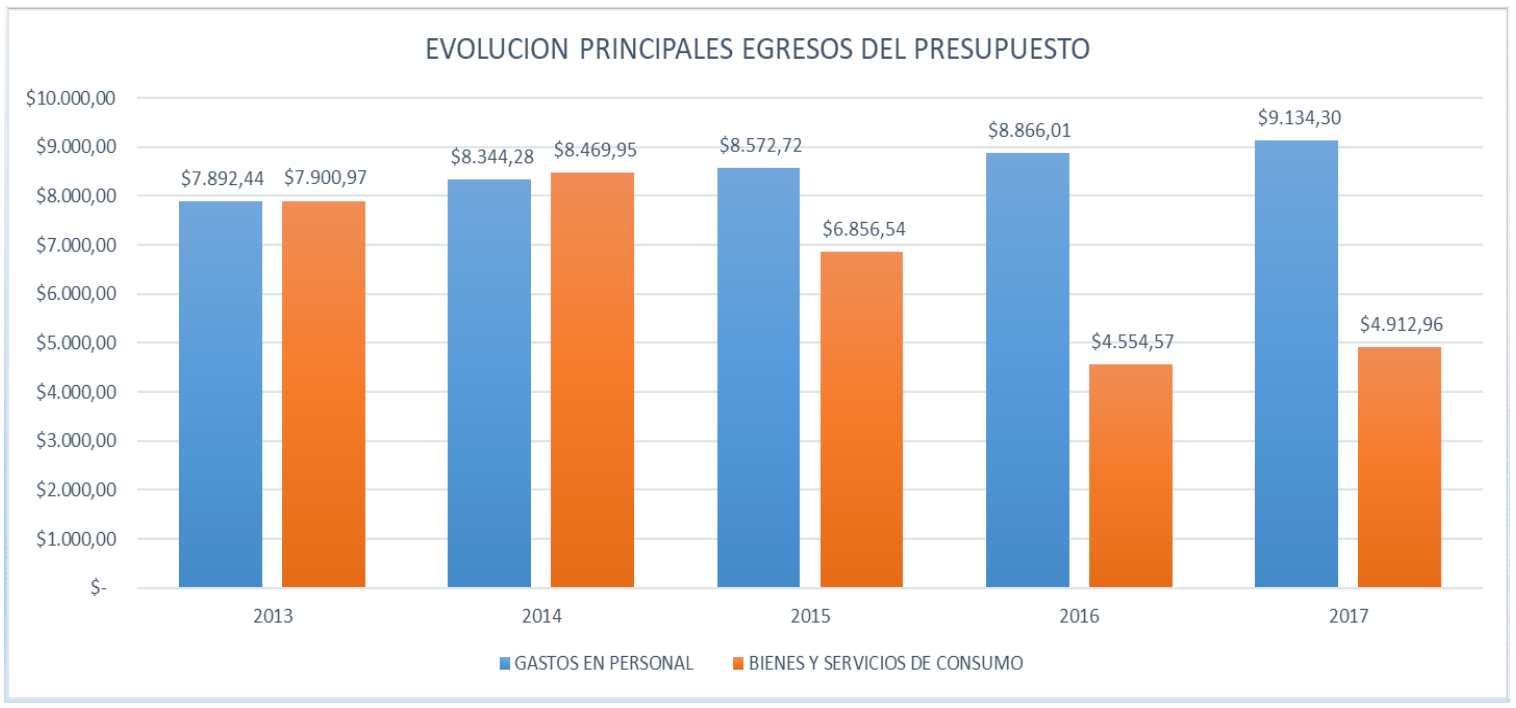

\section{Gráfico 18. Evolución de los principales egresos que conforman el Presupuesto General del Estado, Ecuador, periodo 2013 - 2017 (millones de dólares)}

Fuente: Ministerio de Finanzas del Ecuador

En la presente ilustración se establece un análisis de los principales egresos del presupuesto general del estado ecuatoriano periodo 2013 - 2017 son los gastos en personal y los bienes y servicios para el consumo podemos observar que dentro de los dos primeros años se han mantenido en forma igualitaria mientras que desde el 2015 se ha direccionado más gastos en el personal y menos en los bienes y servicios de consumo, estos resultados se deben al trabajo burocrático que implementa el estado ecuatoriano que es necesario para cumplí con los objetivos planteados en el Plan Nacional del Buen Vivir.

\section{Discusión}

Una vez realizada la investigación se pudo determinar la evolución del Presupuesto General del Estado Ecuatoriano, según los resultado que arrojo la investigación los ingresos y gastos públicos tuvieron su punto fuerte en el año 2014 en comparación al resto de años fiscales que se estudió, dentro de los rubros más significativos en el ingreso es el ingreso tradicional que proviene de recaudación de impuestos se pudo determinar que es el más importante porque genera mayor fondo público, mientras que al hablar del segundo rubro más significativo considerado por historia y antecedentes es el ingreso por venta de petróleo y sus derivados en si durante años atrás era la fuente fundamental del ingreso pero a medida que han pasado los años hemos notado de que ya no genera el ingreso de igual proporción en comparación a años anteriores como podemos notar su punto alto fue en el 2013 de ahí en adelante viene en decrecimiento, pero gracias a la intervención de la política económica implementada por el gobierno la recaudación de tributos que es el rubro más importante ha venido creciendo de años pasados y se mantiene el crecimiento en gran proporción. 


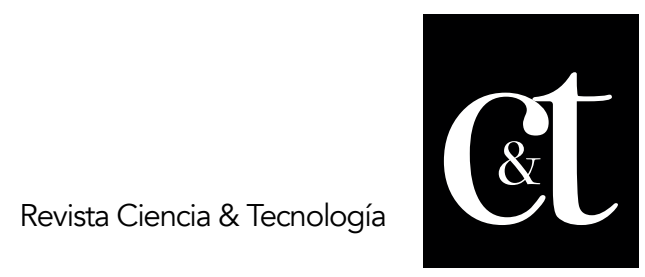

No. 25, 31 de enero de 2020

ISSN impreso: 1390 - 6321

ISSN online: 2661 - 6734

A nivel general el Presupuesto General del Estado en nuestro estudio tuvo un déficit presupuestario en el año 2013 de $\$ 1.313,62$ millones de dólares al igual que en el año 2017 un déficit de \$1.593,29 millones de dólares, mientras que en los demás años estudiados se obtuvieron superávit.

\section{Conclusiones}

El Presupuesto General del Estado se refiere a la planificación de los ingresos y gastos públicos en los cuales los ingresos son generados por el estado mediante las diferentes fuentes de recaudación que sirven para cubrir los gastos que requieren las dependencias del gobierno como sus entidades, instituciones y organizaciones de control, se establece de forma anual y es fundamental para cumplir con las necesidades del pueblo y buscar el bienestar de la población.

En el Ecuador a lo largo de los años desde décadas pasadas el país dependía mucho de los ingresos que generaba por la venta de petróleo y sus derivados, pero con lo que estudiamos y observamos el petróleo en sí, ya no es un recurso que proporciona dichos ingresos como antes, en la actualidad si genera ingresos pero mucho menor a lo que proporcionaba hace años, pero gracias al gobierno a buscado la manera de generar más ingresos y olvidarnos de lo que genera en si el petróleo por eso se fortaleció la recaudación de impuestos que son los que generan más ingresos en la actualidad.

Dentro de los egresos del Presupuesto General del Estado el rubro que genera mayor gasto es el de gasto en personal, esto se debe a que existe una inmensa estructura de organizaciones centralizadas y descentralizadas gubernamentales que conllevan a que este rubro este con una alta necesidad de fondos para cubrirlo el cual es sostenido por los fondos recaudados por los tributos que genera el estado.

\section{Referencias bibliográficas}

Ayala Espino, J. (2001). Economía del sector público mexicano. (Editorial Esfinge). Facultad de Economía, UNAM.

Bernal Torres, C. A. (2006). Metodología de la investigación para administración, economía, humanidades y ciencias sociales. (PEARSON Educación).

León Gutiérrez, A., Escobar Gallo, H., \& Gutiérrez Londoño, E. E. (2007). Hacienda pública: un enfoque económico. Universidad de Medellín.

Ministerio de Economía y Finanzas. Código Orgánico de Planificación y Finanzas Públicas asamblea nacional (2010). Recuperado de: www.finanzas.gob.ec.

Ministerio de Economía y Finanzas. (2017). Directrices para la elaboración de la proforma del Presupuesto General del Estado 2018 y la Programación Presupuestaria cuatrianual 2018-2021. 


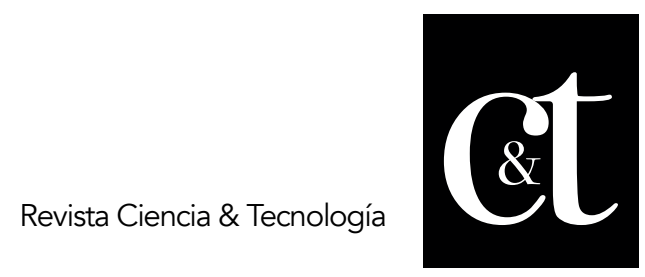

No. 25, 31 de enero de 2020

ISSN impreso: 1390 - 6321

ISSN online: 2661 - 6734

Ministerio de Economía y Finanzas. (2018a). El Presupuesto General del Estado. Recuperado de: https://www.finanzas.gob.ec/el-presupuesto-general- delestado/.

Ministerio de Economía y Finanzas. (2018b). Informe de Ejecución de Presupuesto año 2017. Recuperado de: https://www.finanzas.gob.ec/wpcontent/uploads/downloads/2018/05/Informe-ejecución-presupuestaria 2017.pdf.

Ministerio de Economía y Finanzas. (2018c). Ministerio de Economía y Finanzas Subsecretaría de Presupuesto Normas técnicas de presupuesto. Recuperado de:https://www.finanzas.gob.ec/wp-

content/uploads/downloads/2018/04/Normativa-Presupuestaria-Codificación5-de- abril-de-2018-OK-ilovepdf-compressed.pdf.

Ministerio de Finanzas. (2016). Informe de Ejecución de Presupuesto año 2015. Recuperado de: https://www.finanzas.gob.ec/wpcontent/uploads/downloads/2016/04/Informe-Ejecución-Ejercicio-Fiscal2015.pdf.

Ministerio de Finanzas. (2017). Informe de Ejecución de Presupuesto año 2016. Recuperado de https://www.finanzas.gob.ec/wpcontent/uploads/downloads/2017/11/Informe-Ejec-PGE-2016..compressed.pdf.

Ortiz Bojaca, A. (2005). Fundamentos de finanzas públicas. Colección Estudios de Contaduría. Bogotá: Fundación Universidad de Bogotá Jorge Tadeo Lozano.

Romero Romero, E. (2013). Presupuesto público y contabilidad gubernamental. Ecoe Ediciones. Recuperado de https://books.google.com.ec/books?id=msA0DgAAQBAJ\&printsec=frontcover\& d $q=Q U E+E S+P R E S U P U E S T O+P U ́ B L I C O \& h l=e s-419 \& s a=X \& v e d=0 a h U K E w i 7-$ Zfz2bPcAhVKwlkKHdSOAEYQ6AEIKTAB\#v=onepage\&q\&f=false.

Toro Jaramillo, I. D., \& Parra Ramírez, R. D. (2006). Método y conocimiento: metodología de la investigación: investigación cualitativa/investigación cuantitativa. (Universidad EAFIT). Fondo Editorial Universitario EAFIT. 


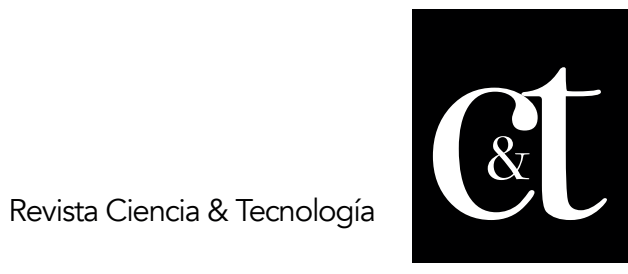

No. 25, 31 de enero de 2020

ISSN impreso: 1390 - 6321

ISSN online: 2661 - 6734

Velásquez Trejo, A. (2010). Ingresos públicos y el principio de la sincronía social y cultural de los impuestos. (Universidad Veracruzana, Xalapa, Veracruz.

Recuperado de: https://www.uv.mx/bdh/files/2014/01/Libro_velasquez.pdf. 